\title{
UJI EFEKTIVITAS SPONSORSHIP PRODUK BEARING RACING PADA PT. SKF INDONESIA PERIODE 2008 - 2012
}

\author{
Septian Willy Yanto; Tomy Gurtama Soemapradja
}

Management Department, School of Business Management, BINUS University Jln. K. H. Syahdan No. 9, Palmerah, Jakarta Barat 11480

gurtama@yahoo.com

\begin{abstract}
The highest achievement of marketing is sales transaction, so the marketing strategy should have impacts on sales. Promotion in the form of sponsorship has just been conducted by PT. SKF Indonesia since 2010-2011. This study aims to analyze the development of bearing products in PT. SKF Indonesia and to test the effectiveness of promotional strategies in the form of motor racing team sponsorship based on average sales of the bearing racing products data. Anova test results showed that the average sales prior to sponsorship were smaller than the average sales after sponsorship. Thus, sponsorship strategy is efective to raise the average of bearing racing product sales in SKF Indonesia with $\alpha=0.05$ and 0.01 .
\end{abstract}

Keywords: sponsorship, anova, bearing racing, SKF

\begin{abstract}
ABSTRAK
Pencapaian tertinggi dari pemasaran adalah terjadi penjualan, sehingga strategi pemasaran harus berdampak pada penjualan. Promosi dalam bentuk sponsorship baru dilakukan PT. SKF Indonesia sejak $2010-$ 2011. Penelitian ini bertujuan untuk menganalisis perkembangan penjualan produk bearing pada PT. SKF Indonesia dan menguji efektivitas strategi promosi dalam bentuk sponsorship pada tim balap motor berdasarkan data rata-rata penjualan produk bearing racing. Hasil uji Anova pada menunjukkan bahwa rata-rata penjualan sebelum melakukan sponsorship lebih kecil daripada rata-rata penjualan sesudah sponsorship. Dengan demikian, strategi sponsorship efektif dapat menaikkan rata-rata penjualan produk bearing racing pada PT. SKF Indonesia dengan $\alpha=0,05$ dan 0,01.
\end{abstract}

Kata kunci: sponsorship, anova, bearing racing, SKF 


\section{PENDAHULUAN}

Strategi dan penerapan promosi yang tepat merupakan suatu kunci untuk mengomunikasikan produk kepada konsumen, Pemilihan bentuk promosi setiap perusahaan sangat berbeda-beda tergantung pada karakteristik produk dan kebijakan pemasaran yang dilaksanakan. Salah satu bentuk promosi yang efektif adalah pelaksanaan sponsorship. Penerapan promosi adakalanya tidak memenuhi sasaran dan hasil yang diharapkan kurang optimal. Hal ini bisa terjadi salah satunya disebabkan pemilihan media yang kurang tepat. Akibatnya, bukan hanya dari segi biaya yang telah dikeluarkan menjadi sia-sia, tetapi juga misi utama perusahaan untuk memperkenalkan produknya menjadi gagal. Untuk itu perlu dilakukan suatu kajian tentang cara penerapan promosi yang tepat dan efektif sehingga dapat mencapai sasaran yang diharapkan.

Sponsorship merupakan suatu kegiatan yang dapat menjadikan nama perusahaan diingat dan dapat meningkatkan citra perusahaan. Sponsorship dilakukan oleh perusahaan dengan tujuan lebih dikenal dan mendapat citra yang baik dari masyarakat dan konsumen. Sponsorship yang dilakukan oleh perusahaan juga dimaksudkan untuk membangun dan memperkuat kepercayaan konsumen terhadap brand image dari produk perusahaan. Brand image yang kuat akan membedakan perusahaan dengan pesaing, karena brand image suatu perusahaan tidak dapat disamakan dengan brand image perusahaan lain. Sponsorship juga merupakan salah satu kegiatan promosi yang dianggap efektif sebagai strategi komunikasi bisnis perusahaan agar namanya bisa dikenal konsumen dan sekaligus melakukan publisitas.

PT. SKF Indonesia berdiri sejak 1997. PT. SKF Indonesia adalah pabrik dan unit bisnis, yang bergerak di bidang produksi bearing kendaraan bermotor. Dengan teknologi SKF, perusahaan ini mampu memenuhi tuntutan pasar, khususnya aplikasi dua-roda (sepeda motor), baik bagi pengguna maupun pabrik-pabrik sepeda motor di seluruh Indonesia. Ini merupakan wujud dari keberhasilan jaringan distribusi dan dealer yang menjangkau seluruh Indonesia, berbagai macam produk Bearing yang di produksi dan di pasarkan oleh PT. SKF Indonesia, seperti SKF Genio, SKF Fitgo, SKF enduro untuk segala jenis sepeda motor. PT. SKF menyediakan solusi teknis bagi para penggemar balap dan bagi pabrikan suku cadang balap di seluruh dunia, dan di Indonesia mulai dari Road Race dan Drag Bike pasti akan menemukan produk dari PT. SKF.

Sejak 2010, SKF Indonesia yang melakukan sponsorship kepada tim balap motor berprestasi di Indonesia dengan mengikuti setiap kejuaraan nasional dan kejuaraan daerah, yang bertujuan agar namanya bisa dikenal di masyarakat dan konsumen sekaligus melakukan publisitas PT. SKF Indonesia. Dengan mengikuti kejuaraan nasional dan kejuaraan daerah motor balap dengan mensponsor tim balap ternama, maka media massa akan meliputnya tanpa PT. SKF Indonesia harus membayar ruang media, dan liputan tersebut akan didengar, dilihat dan dibaca oleh masyarakat dan konsumen, yang dapat membantu dalam upaya membangun dan memperkuat kepercayaan konsumen terhadap brand image produk dari PT. SKF Indonesia. Penelitian ini adalah untuk menganalisis dan menguji serta membuktikan jika ada perbedaan yang signifikan terhadap penjualan sebelum melakukan sponsorship dengan penjualan sesudah melakukan sponsorship.

Berdasarkan latar belakang di atas, permasalahan dalam penelitian ini dapat dirumuskan sebagai berikut. Pertama, bagaimana kondisi penjualan unit bearing sebelum dan sesudah melakukan sponsorship pada PT. SKF Indonesia? Kedua, apakah strategi sponsorship yang di lakukan oleh PT. SKF Indonesia di tim balap motor Indonesia ini efektif terhadap penjualan? Sementara, tujuan penelitian ini adalah pertama untuk melakukan analisis statistik deskriptif data penjualan bearing PT. SKF Indonesia sebelum dan sesudah melakukan strategi promosi sponsorship, dan kedua untuk melakukan uji perbandingan ANOVA rata-rata penjualan bearing PT. SKF Indonesia dari sebelum melakukan strategi promosi sponsorship dan sesudah melakukan strategi promosi sponsorship. 


\section{Tinjauan Pustaka}

Kotler (2002:9) yang diterjemahkan Ancellawati: "Pemasaran adalah suatu proses sosial yang didalamnya individu dan kelompok mendapatkan apa yang mereka butuhkan dan inginkan dengan menciptakan, menawarkan, dan secara bebas mempertukarkan produk yang bernilai dengan pihak lain". Lebih lanjut mengenai pengertian manajemen pemasaran didefinisikan oleh Kotler (2002:10): "Penganalisisan, perencanaan, pelaksanaan, dan pengawasan program-program yang bertujuan menimbulkan pertukaran dengan pasar yang dituju dengan maksud untuk mencapai sasaran perusahaan.” Kotler dan Armstrong (2011:81) menyatakan bahwa bauran pemasaran merupakan sarana taktis perusahaan untuk menentukan positioning yang kuat dalam pasar sasaran. Pemasaran yang efektif memadukan semua elemen bauran pemasaran ke dalam suatu program pemasaran terintegrasi yang dirancang untuk mencapai tujuan pemasaran perusahaan dengan mengantarkan nilai bagi konsumen. Dalam hal ini perusahaan dapat mengendalikan setiap komponen dari marketing mix, yang di dalamnya setiap komponen tersebut harus dibalik untuk menghasilkan pencapaian tujuan secara optimal.

Promosi merupakan salah satu variabel dalam bauran pemasaran yang penting untuk dilaksanakan oleh perusahaan dalam memasarkan barang dan jasa. Kegiatan promosi bukan hanya berfungsi sebagai alat untuk memengaruhi konsumen, melainkan juga sebagai alat untuk memengaruhi konsumen dalam kegiatan pemasaran. Promosi pada hakikatnya adalah suatu komunikasi pemasaran, artinya aktivitas pemasaran yang berusaha menyebarkan informasi, memengaruhi atau membujuk, dan atau mengingatkan pasar sasaran atas perusahaan dan produknya agar bersedia menerima, membeli, dan loyal pada produk yang ditawarkan perusahaan yang bersangkutan, Tjiptono (2001:219). Sementara Sistaningrum (2002:98) mengungkapkan arti promosi adalah suatu upaya atau kegiatan perusahaan dalam memengaruhi "konsumen aktual" maupun "konsumen potensial" agar mereka mau melakukan pembelian terhadap produk yang ditawarkan saat ini atau masa yang akan datang. Konsumen aktual adalah konsumen yang langsung membeli produk yang ditawarkan pada saat atau sesaat setelah promosi produk tersebut dilancarkan perusahaan. Dan konsumen potensial adalah konsumen yang berminat melakukan pembelian terhadap produk yang ditawarkan perusahaan masa yang akan datang. Ada empat jenis kegiatan promosi, antara lain: (Kotler, 2001:98-100), yaitu: periklanan (advertising), yaitu bentuk promosi nonpersonal dengan menggunakan berbagai media yang ditujukan untuk merangsang pembelian; penjualan tatap muka (personal selling), yaitu bentuk promosi secara personal dengan presentasi lisan dalam suatu percakapan dengan calon pembeli yang ditujukan untuk merangsang pembelian; publisitas (publicity), yaitu suatu bentuk promosi nonpersonal mengenai, pelayanan atau kesatuan usaha tertentu dengan jalan mengulas informasi/berita tentangnya (pada umumnya bersifat ilmiah); promosi penjualan (sales promotion), yaitu suatu bentuk promosi di luar ketiga bentuk di atas yang ditujukan untuk merangsang pembelian; dan pemasaran langsung (direct marketing), yaitu suatu bentuk penjualan perorangan secara langsung ditujukan untuk memengaruhi pembelian konsumen.

Untuk melakukan sebuah komunikasi kepada khalayak diperlukan metode. Media yang tepat sesuai dengan tujuan dan khalayak yang dituju dengan beberapa alternatif media, salah satunya adalah sponsorship. Sponsorship didefinisikan sebagai aktivitas komersial, dengan satu pihak memberikan kesempatan kepada pihak lain memanfaatkan berhubungan dengan target khalayaknya dengan tujuan rnendapatkan hasil herupa uang, jasa, ataupun sumber daya (Fill, 2005:713). Copley mengutip dari Sleight yang mendefinisikan sponsorship adalah tentang seseorang yang membayar untuk menjadi bagian dari sesuatu proyek, atau aktivitas, atau tentang seseorang yang membayar untuk menjadi bagian dari sebuah perjanjian kepentingan dengan pihak lain, atau mungkin tentang seseorang yang membuat dirinya bertanggung jawab terhadap hal tertentu (2004:289). Sponsorship dapat memberikan peluang-peluang bagi organisasi sponsor, yaitu: ekspos terhadap khalayak khusus yang setiap event dapat menarik mereka untuk menyampaikan secara sederhana kesadaran pesan-pesan merek, mcmberikan kesan kepada audiens sasaran bahwa ada asosiasi antara pihak yang disponsori dan pihak 
pemberi sponsor dan hal ini merupakan inplikasi dan asosiasi yang mungkin menarik dan atau memberikan keuntungan, memperbolehkan anggota dan audiens sasaran untuk merasakan sponsor secara langsung melalui pesta dan beberapa asosiasi yang bersifat efek negatif dengan media massa tradisional dan bujukan langsung. Selain itu, sponsorship memberikan pihak sponsor kesempatan untuk mencampur berbagal macam alat-alat dalam promotional mix dan menggunakan sumber-sumber dengan lebih efisien dan terbuki lebih efektif. (Fill, 2005:7-13)

Tiga jenis penyediaan sponsor yang masing-masing dibedakan berdasarkan tujuannya, yaitu penyediaan sponsor untuk iklan, penyediaan sponsor untuk pemasaran dan penyediaan sponsor untuk tujuan public relations yang membentuk citra perusahaan. Cakupan bidang sponsor biasanya terjadi dalam pada acara olah raga, acara kebudayaan, penerbitan atau publikasi, pameran, pendidikan, acara amal, dan acara penghargaan. Tujuan Sponsorship bagi public relations antara lain untuk menciptakan atau mempertahankan nama baik, membangun citra perusahaan, sebagai identitas perusahaan dan mengakrabkan nama perusahaan.

Penjualan adalah sasaran inti di antara kegiatan-kegiatan lainnya karena di sini dilakukan perundingan persetujuan tentang serah terima barang serta pembayaran. Konsep penjualan menyatakan bahwa konsumen jika diabaikan biasanya tidak akan membeli produk organisasi dalam jumlah cukup, karena itu organisasi harus melakukan usaha penjualan dan promosi yang agresif (Kotler, 2002:16). Konsep ini mengasumsikan bahwa konsumen malas atau enggan melakukan pembelian dan untuk itu harus didorong. Juga diasumsikan bahwa perusahaan memiliki cara penjualan dan peralatan promosi yang efektif untuk merangsang lebih banyak pembelian. Sesuai dengan tujuan dari pelaksanaan sponsorship yaitu menginformasikan, mengingatkan, membujuk, dan memengaruhi konsumen agar mau membeli dari produk yang dipasarkan oleh pelaksanaan sponsorship tersebut. Wijaya (2006:161) menyebutkan bahwa ada 4 macam langkah sponsorship untuk akhirnya menarik target pasar itu melakukan pembelian. Langkah tersebut, yaitu: pertama, memperoleh atau menarik perhatian para calon konsumen. Setelah dapat menarik perhatian para calon pembeli, langkah berikutnya adalah menimbulkan dan mempertahankan minat mereka. Lalu, langkah ketiga ialah membangkitkan keinginan. Minat yang masih terpendam itu hendaknya dapat menjadi keinginan untuk membeli, dan akhirnya diperoleh sesuatu tindakan dalam bentuk melakukan pembelian. Dengan demikian ada action. Umumnya hubungan antara sponsorship dengan volume penjualan produk adalah positif karena setiap penambahan dana untuk kegiatan sponsorship dapat meningkatkan volume penjualan. Pengurangan dana sponsorship dapat menyebabkan menurunnya volume penjualan yang dicapai. Jika hubungan antara sponsorship dan volume penjualan bersifat negatif, maka penambahan dana untuk kegiatan sponsorship dapat menyebabkan bengkaknya pengeluaran atau meningkatnya kerugian.

\section{METODE PENELITIAN}

Data yang diperoleh dari melalui dua sumber data data primer dari objek penelitian berupa data penjualan sebelum dan sesudah melakukan sponsorship, data promosi, data biaya sponsorship. Data sekunder berasal dari studi pustaka dan buku literatur yang berkaitan dengan masalah penelitian. Statistik Deskriptif digunakan untuk menggali data deskriptif, uji normalitas data untuk menentukan jika data berdistribusi normal (Ghozali, 2006). Uji ANOVA dilakukan untuk menentukan perbedaan signifikan antara rata-rata penjualan sebelum (tahun 2010) dan sesudah melakukan sponsorship. Tahap awal penelitian dimulai dari pengumpulan data dari objek penelitian dan studi literatur, analisis deskriptif, uji normalitas, uji ANOVA, dan berujung pada simpulan dan saran. Hipotesis penelitian yang akan diuji adalah: data penjualan produk bearing racing berdistribusi normal dan rata-rata penjualan produk bearing racing sesudah sponsorship lebih besar daripada rata-rata sebelum melakukan sponsorship. 


\section{HASIL DAN PEMBAHASAN}

Usia 26 tahun bagi sebuah perusahaan bearing merupakan suatu prestasi yang membanggakan. Betapa tidak, semenjak didirikan pabrik bearing pada 1984 ini oleh Wirontono, sampai sekarang masih dapat memenuhi permintaan para konsumen meskipun telah melewati masa krisis moneter yang terjadi pada 1998. Pada mulanya perusahaan ini bernama PT. Logam Sari Bearindo, dan perusahaan ini memulai produksi komersial pada Januari 1986 dan mempunyai merek pasaran yaitu BI (Bearing Indonesia). Pada 1988 PT. Logam Sari Bearindo mengikat perjanjian dengan SKF Swedia yang merupakan produsen bearing terbesar di dunia. Perjanjian tersebut berupa kerja sama teknik yang berguna untuk meningkatkan mutu produksi, sehingga BI dapat bersaing dengan produk-produk import. Pada September 1988, perusahaan Astra Internasional melalui PT. Federal Motor menjadi salah satu pemegang saham PT. Logam Sari Bearindo, Hal itu agar memperkuat struktur permodalan dan pemasaran dan juga menjadikan struktur manajemen menjadi lebih baik. Pada 1992 perusahaan ini mendapat izin usaha tetap dari Departemen Perindustrian Republik Indonesia. Lisensi SKF diberikan untuk semua tipe bearing yang diproduksi. Pada akhir 1992 merek FMB (Federal Motor Bearing) diperkenalkan dan menggantikan merek BI.

Setelah sekian tahun semenjak produksi pertamanya, perusahaan ini mendapatkan sertifikasi ISO 9002 dari lembaga sertifikasi Llyod's Register Quality Assurance ( LRQA) pada Januari 1996. Hal ini membuktikan dedikasi pihak manajemen terhadap kualitas manajemen perusahaan yang sudah diakui oleh internasional. Pada September 1997, PT. Logam Sari Bearindo sudah resmi menjadi bagian dari SKF Swedia, kemudian berganti nama menjadi PT. SKF Indonesia. Tentunya hal ini menjadikan produk-produk yang diproduksi memiliki standar dengan SKF Swedia, dan juga tentunya kualitas dan spesifikasi produk akan sama dengan produk yang berasal dari PT. SKF di seluruh negara. Kemudian demi memenuhi standar manajemen lingkungan, perusahaan mendapatkan sertifikat ISO 14001 pada Desember 1999, dan juga pada bulan yang sama mendapatkan sertifikat ISO 9000.

Pada Januari 2000, diperkenalkan sebuah merek dagang baru yaitu SKF Enduro dan SKF Genio SKF Fitgo. Kemudian pada Desember 2000, Suzuki sebagai salah satu customer utama memberikan penghargaan sebagai produk bearing yang memiliki kualitas terbaik. Dengan memiliki beberapa sertifikasi produk PT. SKF Indonesia mampu memasuki pasar internasional yang dimulai pada Oktober 2000 dengan mengekspor produk ke Malaysia. Pada Maret 2004 PT. SKF Indonesia mendapatkan sertifikasi ISO/TS 16949. Dari tahun ke tahun perkembangan perusahaan ini semakin meningkat, hal itu ditunjukkan dengan memperluas area pabrik dalam rangka memenuhi banyaknya permintaan pelanggan yang datang baik dari lokal maupun internasional. Bentuk hukum perusahaan PT. SKF Indonesia adalah perseroan terbatas. Badan hukum yang merupakan persekutuan modal, didirikan berdasarkan perjanjian, melakukan kegiatan usaha dengan modal dasar yang seluruhnya terbagi dalam saham dan memenuhi persyaratan yang ditetapkan dalam Undang-Undang ini serta peraturan. PT. SKF Indonesia memiliki beberapa fasilitas di dalam pabrik untuk para karyawan dalam menyalurkan hobi dan kreativitas mereka, seperti dengan adanya beberapa sarana olahraga seperti lapangan bulu tangkis, lapangan futsal, dan lapangan voli. Begitu pula PT. SKF Indonesia menyediakan studio band untuk para karyawannya dalam menyalurkan bakat dan hobi mereka guna membuat kinerja mereka terhadap perusahaan terjaga.

Pabrikan motor Indonesia telah memercayai untuk memakai bearing mesin dan roda produksi PT. SKF Indonesia. Semua jenis motor dan merek pabrikan Indonesia memakai bearing yang diproduksi PT. SKF Indonesia. PT. SKF Indonesia memasok bearing ke pabrikan motor di Indonesia dengan jenis bearing standar, berbeda dengan bearing yang dijual pasaran. Jenis bearing yang dijual di pasaran yaitu bearing inovasi atau bearing racing untuk motor sport atau motor balap. Produk yang dipasarkan adalah SKF Enduro, SKF Genio, SKF Fitgo. Ketiga produk tersebut adalah bearing inovatif yang menjadi tren baru untuk aplikasi sepeda motor. Kombinasi sangkar bola fiber (kode: 
TN9) yang ringan dan pelumasan terintegrasi membuat putaran bearing menjadi ringan dan halus serta menghasilkan tarikan lebih responsif pada mesin motor. Bearing ini sangat cocok bagi penyuka motor sport atau pecinta motor balap. Kemampuan meredam noise pada mesin adalah keunggulan SKF Enduro, Genio, FitGo. Keunggulan spesifikasi SKF Enduro, Genio, FitGo, dibandingkan bearing standar memberikan manfaat dalam hal peningkatan umur bearing dan temperatur operasi, serta membuat putaran menjadi lebih ringan. PT. SKF Indonesia melakukan sponsorship dengan mensponsori 3 tim balap motor Indonesia yang mengikuti berbagai macam kejuaran nasional dan kejuaraan daerah. Tujuan PT. SKF Indonesia mesponsori tim balap motor adalah untuk meningkatkan penjualan produk racing yang dipasarkan di pasar otomotif Indonesia. Ketiga tim balap yang disponsori oleh PT SKF Indonesia dan berprestasi pada 2010-2011: Wahana Dunia Motor Racing Team, Jayadi Racing Team, Jeany Joo Racing Team. Ketiga tim tersebut disponsori dengan pasokan bearing racing dengan nominal yang dikeluarkan PT. SKF Indonesia senilai Rp 150 juta per tahun untuk keseluruhan tim. PT. SKF Indonesia mulai melakukan sponsorship kepada tim balap berprestasi pada awal 2010 hingga saat ini. Berikut ini data penjualan PT. SKF Indonesia sebelum dan sesudah melakukan sponsorship; data diambil 2 tahun sesudah melakukan sponsorship, dan 2 tahun sebelum melakukan sponsorship. Karena keterbatasan data dari perusahaan, peneliti menganalisis sponsorship dalam bentuk kelompok Bearing Racing yang diuraikan bulanan sebagai berikut.

\section{Analisis Deskriptif Penjualan Sebelum Melakukan Sponsorship}

Hasil analisis statistik deskriptif menunjukkan bahwa penjualan minimum PT. SKF Indonesia di 2008 sampai 2009 terjadi pada Maret 2008, yang mencapai angka 1578 unit bearing yang terjual. Sedangkan penjualan maksimum PT. SKF Indonesia di 2008 sampai 2009 terjadi pada September 2009 sekitar 3528 unit bearing yang terjual. Rata-rata penjualan bearing PT. SKF Indonesia di 2008 sampai 2009 adalah sekitar 2594 unit.

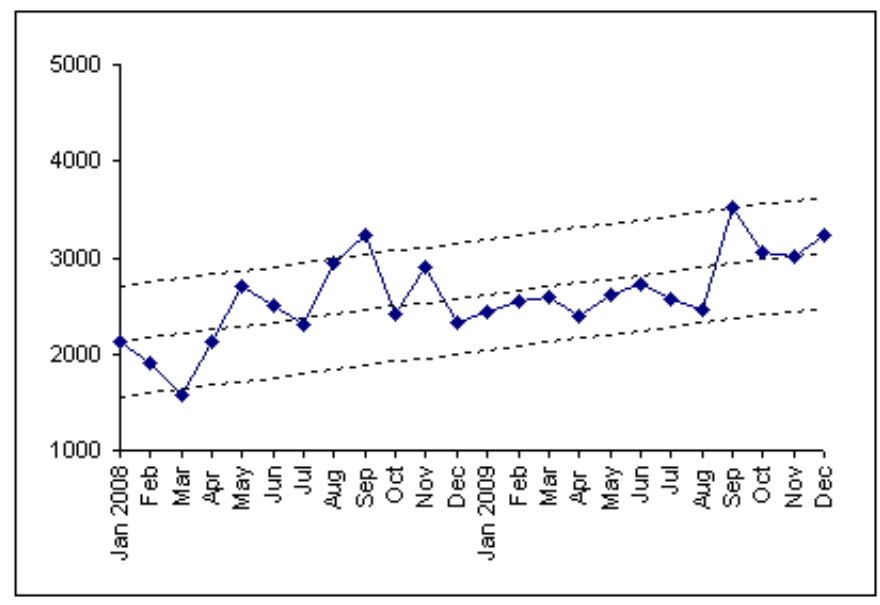

Gambar 1 Penjualan Sebelum Melakukan Sponsorship

Tabel 1 Statistik Deskriptif Penjualan Sebelum Melakukan Sponsorship

\begin{tabular}{lrlr}
\hline Mean & 2594.54 & Skewness & -0.014 \\
Standard Error & 90.88 & Range & 1950 \\
Median & 2562.5 & Minimum & 1578 \\
Standard Deviation & 445.23 & Maximum & 3528 \\
Sample Variance & 198235.30 & Sum & 62269 \\
Kurtosis & 0.30 & Count & 24 \\
\hline
\end{tabular}


Fluktuasi penjualan selama 2008-2009 kurang lebih sebesar 445 unit. Artinya, penjualan pada bulan berikutnya dapat bertambah atau berkurang 445 unit dari penjualan bulan sebelumnya. Hal ini ditunjukkan dari deviasi standar berdasarkan analisis statistik deskriptif tersebut. Analisis regresi sederhana data penjualan 2008-2009 menunjukkan tren yang meningkat, dilihat dari kemiringan garis regresi sederhana sebesar 40,56. Arti, setiap bulan cenderung bertambah kurang lebih 40 unit.

\section{Analisis Deskriptif Penjualan Sesudah Melakukan Sponsorship}

Hasil analisis statistik deskriptif menunjukkan bahwa penjualan minimum PT. SKF Indonesia di 2010 sampai 2011 terjadi pada Oktober 2010, yang mencapai angka 3217 unit bearing yang terjual. Sedangkan penjualan maksimum PT. SKF Indonesia di 2010 sampai 2011 terjadi pada November 2011 sekitar 4236 unit bearing yang terjual. Rata-rata penjualan PT. SKF Indonesia di 2010 sampai 2011 adalah sekitar 3701 unit bearing yang terjual. Artinya, rata-rata penjualan 2010-2011 lebih besar dari rata-rata penjualan 2008-2009 (3701 > 2594).

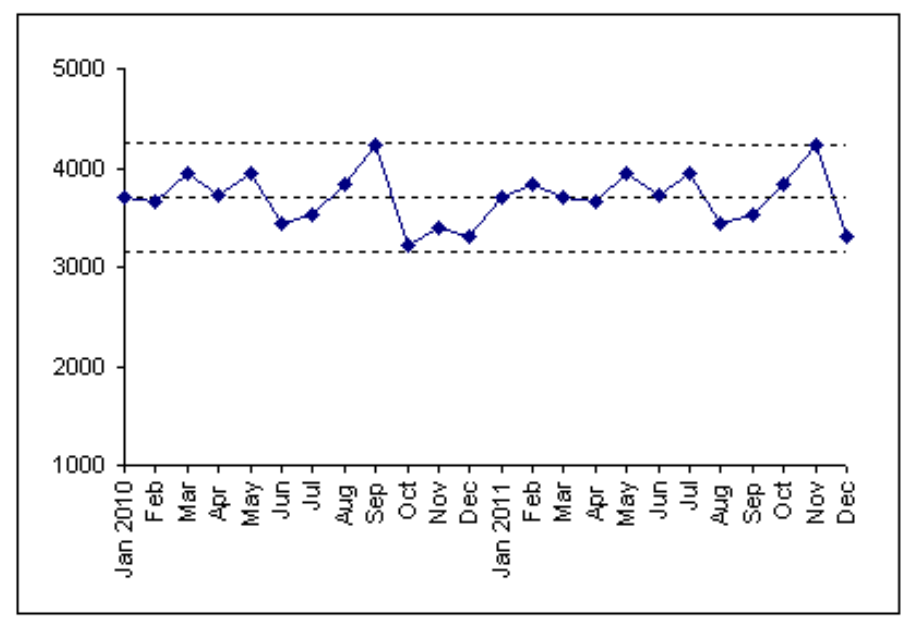

Gambar 2 Penjualan Sesudah Melakukan Sponsorship

Tabel 2 Statistik Deskriptif Penjualan Sesudah Melakukan Sponsorship

\begin{tabular}{lclc}
\hline Mean & 3701.125 & Skewness & 0.16 \\
Standard Error & 55.22 & Range & 1019 \\
Median & 3708 & Minimum & 3217 \\
Standard Deviation & 270.53 & Maximum & 4236 \\
Sample Variance & 73190.54 & Sum & 88827 \\
Kurtosis & -0.29 & Count & 24 \\
\hline
\end{tabular}

Fluktuasi penjualan selama 2010-2011 kurang lebih sebesar 270 unit. Artinya, penjualan pada bulan berikutnya dapat bertambah atau berkurang 270 unit dari penjualan bulan sebelumnya. Dengan demikian, penjualan di 2010-2011 lebih stabil dari penjualan 2008-2009 karena deviasi standar 20082009 lebih besar daripada deviasi standar 2010-2011 (445 > 270). Tujuan akhir sponsorship dapat tercapai yang didukung data penjualan sesudah melakukan sponsorship, tetapi harus dibuktikan lewat uji Anova untuk menguji efektivitas. Bila efektif, artinya strategi tersebut signifikan menaikkan penjualan. 


\section{Uji Normalitas}

Uji Normlitas dilakukan untuk mengetahui jika variabel-variabel data penjualan PT. SKF Indonesia berdistribusi normal atau tidak. Sebagai alat statistika parametric, maka untuk dapat menggunakan rumus ANOVA harus terlebih dahulu perlu dilakukan uji asumsi meliputi normalitas (Ghozali, 2009).

Tabel 3 Uji Normalitas

\begin{tabular}{lccccc}
\hline & \multicolumn{3}{c}{ Kolmogorov-Smirnov $^{\text {a }}$} & \multicolumn{2}{c}{ Shapiro-Wilk } \\
\cline { 2 - 6 } & Statistic & df & Sig. & Statistic df Sig. \\
\hline Data_Penjualan & .114 & 48 & .152 & .953 & 48.051 \\
\hline a. Lilliefors Significance Correction & & & & \\
\hline
\end{tabular}

Tabel di atas menunjukkan bahwa nilai sig $>0,05$. Ini berarti bahwa data penjualan sebelum dan sesudah melakukan sponsorship berdistribusi normal. Dengan kata lain, sebaran nilai data penjualan sebelum melakukan sponsorship dan sesudah melakukan sponsorship berbentuk seperti atau mendekati kurva lonceng terbalik atau seperti kurva berdistribusi normal.

\section{Uji Anova}

Uji Anova One Way dilakukan untuk melihat jika ada perbedaan dari kedua data penjualan PT SKF Indonesia sebelum melakukan sponsorship dan sesudah melakukan sponsorship. Tujuan akhir sponsorship dapat tercapai yang didukung data penjualan sesudah melakukan sponsorship, tetapi harus dibuktikan uji Anova untuk menguji efektivitas. Berikut adalah hasil uji Anova One Way dari kedua data penjualan PT. SKF Indonesia.

Tabel 4 Uji Homogenitas

\begin{tabular}{|cccc}
\hline \multicolumn{4}{c}{ Test of Homogeneity of Variances } \\
\hline \multicolumn{4}{c}{ Data_Penjualan } \\
\hline Levene Statistic & df1 & df2 & Sig. \\
\hline 3.584 & 1 & 46 & .065 \\
\hline
\end{tabular}

Tabel di atas menunjukkan bahwa Sig $=0.065>\alpha 0.05$. Ini berarti Ho ditolak, sehingga Hi diterima. Dengan demikian kedua data penjualan sebelum dan sesudah melakukan sponsorship memiliki varian yang sama.

Tabel 5 Uji Anova dengan $\alpha=0,05$

\begin{tabular}{lrrrrr}
\hline \multicolumn{5}{c}{ ANOVA } \\
\hline \multicolumn{7}{c}{ Data_Penjualan } \\
\hline & Sum of Squares & \multicolumn{1}{c}{ df } & Mean Square & \multicolumn{1}{c}{ F } & \multicolumn{1}{c}{ Sig. } \\
\hline Between Groups & 14694320.083 & 1 & 14694320.083 & 108.275 & .000 \\
Within Groups & 6242794.583 & 46 & 135712.926 & & \\
Total & 20937114.667 & 47 & & & \\
\hline
\end{tabular}

Tabel di atas menunjukkan bahwa $\mathrm{F}$ uji $=108.275$, sedangkan $\mathrm{F}$ table atau $\mathrm{Sig}=0.00$. Ini berarti $\mathrm{F}$ uji $>$ Sig sehingga Ho ditolak, sehingga Hi diterima. Dengan demikian uji Anova menyimpulkan rata-rata penjualan sebelum melakukan sponsorship lebih kecil dari rata-rata penjualan 
sesudah melakukan sponsorship dengan tingkat kepercayaan 95\% atau $\alpha 5 \%$. Dengan kata lain, strategi sponsorship efektif dapat meningkatkan rata-rata penjualan bearing.

Uji Anova akan dilakukan kembali dengan tingkat signifikan $\alpha=0,01$ untuk melakukan uji statistik dengan tingkat akurasi yang lebih tinggi (tingkat kepercayaan 99\%).

Tabel 6 Uji Anova dengan $\alpha=0,01$

\begin{tabular}{lrrrrrc}
\hline \multicolumn{6}{c}{ ANOVA } \\
\hline \multicolumn{7}{c}{ Data_Penjualan } \\
\hline Sum of Squares & df & Mean Square & \multicolumn{1}{c}{ F } & \multicolumn{1}{c}{ Sig. } \\
\hline Between Groups & 14694320.083 & 1 & 14694320.083 & 108.275 & .000 \\
Within Groups & 6242794.583 & 46 & 135712.926 & & \\
Total & 20937114.667 & 47 & & & & \\
\hline
\end{tabular}

Tabel di atas menunjukkan bahwa $\mathrm{F}$ uji $=108.275$ sedangkan $\mathrm{F}$ table atau Sig $=0.00$. Artinya, $\mathrm{F}$ uji $>$ Sig sehingga Ho ditolak, dan Hi diterima. Dengan demikian uji Anova menyimpulkan rata-rata penjualan sebelum melakukan sponsorship lebih kecil dari rata-rata penjualan sesudah melakukan sponsorship dengan tingkat kepercayaan $99 \%$ atau $\alpha$ 1\%. Dengan kata lain, strategi sponsorship efektif dapat meningkatkan rata-rata penjualan bearing.

\section{SIMPULAN}

Simpulan yang diperoleh dari penelitian ini adalah sebagai berikut. Pertama, penjualan bearing PT. SKF Indonesia sesudah sponsorship lebih besar dari pada sebelum melakukan sponsorship (3217 unit $>1578$ unit). Penjualan maksimum bearing sesudah melakukan sponsorship lebih besar dari maksimum penjualan sebelum melakukan sponsorship (4236 unit > 3528 unit). Ratarata penjualan bearing sesudah melakukan sponsorship lebih besar dari rata-rata penjualan tanpa sponsorship (3701 unit > 2594 unit). Kedua, berdasarkan deviasi standar, fluktuasi penjualan sesudah melakukan sponsorship lebih kecil. Artinya, penjualan sesudah melakukan sponsorship lebih stabil (270 unit $<445$ unit). Ketiga, uji ANOVA menunjukkan rata-rata penjualan sebelum melakukan sponsorship secara signifikan lebih kecil daripada sesudah melakukan sponsorship. Artinya, strategi sponsorship secara efektif dapat meningkatkan penjualan bearing pada PT. SKF Indonesia $(\alpha=0,05$ dan 0,01$)$.

Sementara, beberapa saran yang dapat disampaikan adalah sebagai berikut. Pertama, walaupun hasil penelitian ini menunjukkan bahwa strategi promosi sponsorship dapat meningkatkan penjualan bearing, dengan rata-rata penjualan sesudah melakukan sponsorship lebih besar dari pada sebelum melakukan sponsorship, strategi ini akan dengan mudah ditiru perusahaan lain. Perusahaan harus tetap mengembangkan strategi lain terutama yang sulit ditiru oleh pesaing, misal meningkatkan kualitas produk bearing racing. Hal ini berhubungan dengan meningkatkan kualitas material, ukuran presisi bearing racing, mengurangi tingkat kebisingan bearing racing sekaligus mengurangi tingkat gesekan bearing yang berujung pada daya tahan produk (endurance). Kedua, di mata konsumen saran nomor satu akan berdampak pada kenaikan harga. Jika kenaikan harga tidak diimbangi dengan informasi peningkatan kualitas material dan daya tahan, akan dengan mudah konsumen berpaling ke produk pesaing. Ketiga, sponsorship yang dilakukan sekarang adalah memberikan sponsorship dengan memasok bearing racing pada tim peserta. Jika suatu saat kondisi keuangan perusahaan sudah jauh lebih baik, perusahaan bisa saja terlibat sebagai sponsorship di event balap, bahkan bisa juga sebagai sponsorship tunggal. Keempat, PT. SKF Indonesia untuk memperluas segmen pasarnya, seperti memulai menjual bearing racing untuk mobil karena penggemar mobil sport sangat konsumtif dalam 
menggunakan bearing racing. Jika perusahaan ingin memulai menjual bearing racing untuk mobil di pasaran, dapat dimulai dengan mensponsori tim balap mobil berprestasi untuk meningkatkan penjualan bearing racing. Kelima, PT. SKF Indonesia memberikan perbandingan test drive kendaraan yang memakai bearing racing dengan kendaraan yang tidak menggunakan bearing racing, agar konsumen lebih yakin dalam memilih produk bearing racing PT. SKF Indonesia.

\section{DAFTAR PUSTAKA}

Fill, C. (2005) Marketing Engagement, Strategies and Practice. $4^{\text {th }}$ ed. New Jersey: Prentice Hall.

Ghozali, I. (2006). Aplikasi Analisis Multivarite dengan SPSS. Cetakan Keempat. Semarang: Badan Penerbit Universitas Diponegoro.

Kotler, P. (2001). Manajemen Pemasaran di Indonesia. Jakarta: Salemba Empat.

. (2002). Manajemen Pemasaran: Analisis, Perencanaan, Implementasi dan Kontrol. Terjemahan oleh Teguh, H., dan Rusly, R. A. Edisi 9, Jilid 1 dan 2. Jakarta: Prenhalindo.

Kotler dan Armstrong. (2011). Marketing on Introduction. New Jersey: Pearson Education.

O'Brien, J. A. (2003). Introduction to Information System Essential for E-Business Enterprise Eleventh Edition. New York: McGraw-Hill.

Sistaningrum, W. (2002). Manajemen Penjualan Produk. Cetakan I. Yogyakarta: Kanisius.

Tjiptono, F. (2001). Manajemen Jasa. Yogyakarta: Andi.

Wijaya. (2006). Pengantar Ilmu Komunikasi. Medan: Pustaka Bangsa. 